\title{
ANÁLISE DAS TÉCNICAS DE CONTENÇÃO E ESTABILIZAÇÃO \\ DE SOLOS EM ENCOSTAS COM OCUPAÇÃO ANTRÓPICA
}

\author{
Bianca Fukuhara Yazaki \\ Gabriel Menegassi Pereira da Silva \\ Raphael Lacerda Vasconcelos \\ Victor Shen Tin Hsieh \\ Kamila Rodrigues Cassares Seko \\ Universidade Presbiteriana Mackenzie (UPM)
}

\begin{abstract}
Resumo
Este trabalho objetiva estudar as soluçôes técnicas possíveis para proporcionar a estabilidade de encostas compostas por solo. Sabe-se que a ocupação antrópica e desordenada de encostas é comum no Brasil devido ao déficit habitacional. Com esse foco, foram estudados os métodos de estabilização, buscando levantar suas limitaçóes executivas para, então, compor uma matriz de tomada de decisão. Essa matriz apresenta como principais parâmetros de entrada o método de contenção, a altura limite da contenção, a possibilidade de sua aplicação abaixo do nível d'água (NA) e a possível necessidade de acesso de maquinário pesado. Com o intuito de aplicá-la, foram selecionadas três obras de estabilização de encostas que ocorreram na subprefeitura de São Mateus, município de São Paulo. Após análises críticas das possíveis soluçóes obtidas por meio da matriz, verificou-se bom desempenho ao empregar a matriz em uma situação de instabilidade de encosta real.
\end{abstract}

Palavras-chave: Ocupação antrópica. Estabilidade de encosta. Matriz de tomada de decisão. 


\section{INTRODUÇÃO}

Diversas regiôes do Brasil apresentam ocupaçôes irregulares em locais com relevo acidentado, onde os escorregamentos têm sido constantes nos últimos anos, principalmente nas épocas com um alto volume pluviométrico. Em época de chuvas, muitas tragédias insanáveis acontecem, como perdas humanas, danos ambientais e perdas materiais e, consequentemente, gera-se um grande número de pessoas desabrigadas.

De acordo com o Instituto Brasileiro de Geografia e Estatística - IBGE (2018), entre os estados da região Sudeste com maior número de habitantes em área de risco, Sáo Paulo destaca-se com 1.521.386 habitantes divididos entre os municípios monitorados, seguido por Minas Gerais, Rio de Janeiro e Espírito Santo. Além disso, o levantamento mostrou que a capital do estado paulista e alguns municípios da região metropolitana concentram grande parte desses moradores situados em áreas de risco. Com esses dados, pode-se destacar a importância do desenvolvimento de estudos e proposiçóes de solução para as áreas de risco na cidade de São Paulo. Para construir moradias nesses locais, a população retira a cobertura vegetal, expondo o solo às intempéries; lança águas servidas a céu aberto; executa cortes com declividade e alturas excessivas, e aterros, inadequadamente, proporcionando a ocorrência de processos erosivos e os movimentos de massa (GIRÃO; CORRÊA; GUERRA, 2007).

Dessa maneira, é necessário que medidas sejam tomadas para evitar esses desastres, como a conscientização da população e a realização de estudos que identifiquem os melhores métodos de contenção a serem aplicados, visando à estabilização do maciço de terra, sendo esta uma das medidas mais necessárias conforme sugere Mesavilla (2019). Deve-se também levar em consideração que são áreas com menor índice de desenvolvimento no campo das políticas públicas, em que há limitação quanto à infraestrutura e às condições dignas de habitação.

Até onde os autores têm conhecimento, as publicaçóes geralmente se propóem a apresentar meios para o monitoramento das áreas de risco, como apresentado por Souza et al. (2017), Soares e Pereira (2017), e Leite, Pinheiro e Pamboukian (2019) ou, de forma simplificada, projetos desenvolvidos ou soluçôes técnicas empregadas em encostas, principalmente para rodovias como em Rios Filho et al. (2013) e Cortez et al. (2017).

Este trabalho é um recorte de uma pesquisa maior que está em desenvolvimento, que tem o intuito de compreender e propor soluçóes técnicas de estabilização e/ou contenção exequíveis em áreas de ocupação desordenada. Neste recorte, objetiva-se analisar as soluçóes técnicas para a estabilização e contenção de encostas em áreas 
urbanas com ocupação antrópica, baseando-se em limitações técnicas dos métodos a serem estudados; busca estabelecer, assim, uma matriz de tomada de decisão com as técnicas de contenção abordadas e, então, realizar a sua aplicação em casos reais locados no distrito de São Mateus, em São Paulo.

\section{REVISÁO DA LITERATURA}

A seguir, serão apresentados os principais conceitos de instabilidade de encostas e as características das soluçôes técnicas tratadas nas próximas seçôes deste trabalho. Para uma rápida contextualização, os autores pedem licença para tratá-los de forma breve.

\subsection{Movimentos de massa e risco geológico}

De acordo com o GeoRio (2000a), os movimentos de massa podem ser classificados em quatro principais grupos:

1. quedas: segundo o Centro Nacional de Monitoramento e Alerta de Desastres Naturais - Cemaden (2016), são movimentos gravitacionais de solos em volumes variáveis;

2. escorregamentos: Pessôa Neto (2013) define como movimentos de solo e rocha superficiais com ruptura bem definida;

3. corridas: são movimentos de massa rápidos e desordenados, também de acordo com Cemaden (2016).

4. rastejos: são movimentos gravitacionais lentos e contínuos das camadas superficiais do solo.

Quanto à probabilidade de ocorrência do processo ou risco geológico, podem ser empregados os critérios de classificação em: R1 (baixo), em que há a inexistência de indícios de desenvolvimento de processos e não ocorrência de acidentes; R2 (médio), que apresenta poucas evidências de desenvolvimento de processos e uma pequena possibilidade de ocorrer acidentes; R3 (alto), em que se tem evidências significativas de desenvolvimento de processos e probabilidade de ocorrência de eventos destrutivos; e R4 (muito alto), em que há grande probabilidade de ocorrência de acidentes (MINISTÉRIO DAS CIDADES; INSTITUTO DE PESQUISAS TECNOLÓGICAS, 2007). 


\subsection{Importância da drenagem}

Os projetos de drenagem superficial têm como objetivo melhorar as condiçóes de estabilidade, reduzindo a infiltraçáo ao talude. Independentemente da solução que seja adotada para garantir a estabilização da encosta, devem-se aplicar projetos que combinem aspectos de drenagem e proteção superficial (GEORIO, 2000b).

Ainda segundo GeoRio (2000b), um sistema de drenagem superficial deve ser capaz de captar e conduzir as águas incidentes à superfície do talude, considerando toda a bacia de captação.

\subsection{Retaludamento}

O método de retaludamento é bastante empregado para garantir estabilidade em taludes. Trata-se de uma técnica de alteração das características geométricas do solo simples e que emprega a terraplanagem com alteração de corte/aterro, garantindo, assim, maior estabilidade ao solo (MASSAD, 2010).

\subsection{Muros e cortinas}

Muro de arrimo ou muro de contenção é uma estrutura projetada para conter o solo das encostas, quando existe um desnível no terreno, segundo Gerscovich (2012). Esses muros podem ser divididos em dois grupos: gravidade e flexão. Os muros de gravidade dependem de características geométricas e do próprio peso para a sua estabilização de contenção (GEORIO, 2000c). Já os muros de flexão são feitos de concreto armado, tornando-os mais onerosos e esbeltos, também capazes de suportar cargas maiores (GERSCOVISH, 2012).

Como muros de gravidade têm-se:

1. Muro de gabião: são muros construídos por meio de superposição de "gaiolas" de malhas de arame galvanizado preenchidos de pedras (HACHICH et al., 1998).

2. Crib wall: de acordo com Hachich et al. (1998), são muros compostos de estruturas pré-moldadas agrupadas em formatos de "fogueiras" justapostas e interligadas longitudinalmente, com seu espaço interno preenchido com material granular graúdo.

3. Solo pneu: muros construídos a partir de camadas horizontais de pneus, que são preenchidas com solo compactado e amarados com arames ou cordas (GEORIO, 2000c). 
4. Sacaria de solo cimento (rip-rap): segundo o Departamento Nacional de Infraestrutura se Transporte - DNIT (BRASIL, 2006), são muros constituídos de sacos de plásticos ou aniagem e preenchidos por misturas de solos locais e cimento Portland.

O muro de flexão mais comumente usado é o muro em "L", assim denominado por resistir aos esforços de empuxo através da flexão; é constituído de concreto armado e considerada uma estrutura esbelta (HACHICH et al., 1998).

Ainda como método de contenção, têm-se as cortinas que, segundo Hachich et al. (1998), são compostas de paramentos de concreto armado ou projetado, que normalmente tendem a ser escorados por tirantes ou bermas durante sua fase executiva e travamento da cortina por meio da estrutura quando a obra estiver pronta.

É dessa forma que se constitui a cortina atirantada - um muro de concreto armado sem base, com tirantes protendidos que permitem a contenção de taludes naturais e de corte (SOLOTRAT ENGENHARIA GEOTÉCNICA EIRELI, 2018).

Além desses métodos já apresentados, ainda podem ser elencados os seguintes:

1. Estaca raiz: em referência a Geofix (2018), pode-se definir esse método como um conjunto de estacas argamassadas in loco com emprego de um revestimento e diâmetros de até $500 \mathrm{~mm}$ e $52 \mathrm{~m}$ de profundidade, que, alinhadas de acordo com o projeto, são responsáveis por contenção de empuxos provenientes do solo. Sua diferenciação é que sua estaca possui armadura ao longo de todo o comprimento.

2. Microestaca: de acordo com o GeoRio (2000d), esse método também consiste em estacas moldadas in loco, mas com diâmetros de até $400 \mathrm{~mm}$. Em seu método construtivo, a concretagem é feita por meio de injeção de argamassa sob pressão ou calda de cimento na bainha, formando travamentos laterais ao fuste da estaca (SOLOTRAT ENGENHARIA GEOTÉCNICA EIRELI, 2018).

\subsection{Reforço de solo}

Reforço de solos é um método que pode ser aplicado na recomposição de taludes, por meio da inserção ou inclusão de materiais resistentes à tração (MASSAD, 2010). Entre inúmeros métodos da Engenharia Geotécnica, destacam-se:

1. Solo grampeado: consiste em estabilizaçôes rápida, temporária ou permanente, por meio do emprego de chumbadores que reforçam o maciço, utilizada em conjunto ao concreto projetado e armado com tela de aço eletrossoldada (HACHICH et al., 1998). 
2. Terra armada: na definição de Hachich et al. (1998), esse método consiste em estruturas formadas por placas (em geral pré-moldadas), aterro e armaduras metálicas que contribuem para o travamento e sustentação da contenção.

3. Jet-grouting: é um processo que utiliza ar, água e calda de cimento em uma combinação adequada, injetando-os sob altas pressôes, formando corpos cilíndricos no maciço. A técnica pode ser aplicada em quaisquer direçóes, desde vertical até horizontal, de modo a atingir a resistência prevista em projeto (HACHICH et al., 1998).

4. Geomantas: segundo a Defesa Civil do Espírito Santo (2017), esse método consiste na aplicação de materiais sintéticos que não degradam e oferecem ancoragem para as raízes da vegetação implantada no talude.

\section{METODOLOGIA}

Tendo como base as soluçóes para a estabilização de encostas apresentadas por GeoRio (2000c; 2000d) e Luz et al. (2019), adotou-se uma estratégia de pesquisa para este estudo, que consistiu em uma análise de levantamentos bibliográficos sobre as técnicas executivas vigentes, a respeito das possíveis soluçóes empregadas para estabilização e/ou contenção de encostas constituídas por solos, e sua boa prática presente na literatura tradicional sobre o tema.

Após a coleta do material, as informaçóes sobre os métodos selecionados foram compiladas na forma de uma matriz de tomada de decisão, contemplando vantagens, desvantagens, limitaçóes executivas quanto à presença do nível d'água, desnível máximo possível de ser vencido e facilidade de acesso de maquinário para a execução da matriz.

Destaca-se que os autores deste trabalho consideraram essas informaçóes importantes para a escolha de soluçóes técnicas em um primeiro momento de elaboração de um estudo de viabilidade técnica. Para uma verificação preliminar do comportamento dessa matriz, foi realizado um estudo de caso sobre algumas encostas localizadas na Subprefeitura de São Mateus (São Paulo, SP), por meio das informaçôes apresentadas por São Paulo (2010a; 2010b).

Foram selecionados três locais com instabilidade relatada e que também apresentassem soluçôes técnicas executadas. O intuito dessa etapa foi verificar se a solução executada estava compreendida entre as possíveis soluçóes apresentadas pela matriz. $\mathrm{Na}$ sequência, os apresentaremos uma breve ponderação entre os principais parâmetros 
que interferem na escolha da solução técnica e a sua viabilidade executiva. Também se escolheu uma quarta região sem nenhuma solução proposta por São Paulo (2010a; 2010b) para a aplicação da matriz proposta aqui proposta.

\section{PESQUISA PRÁTICA}

\subsection{Elaboração da matriz de tomada de decisáo}

Com base na revisão de literatura realizada, foram levantados parâmetros básicos que se fazem importantes durante a escolha do método de contenção ou estabilização a ser utilizado em determinada área de risco. Os parâmetros levantados podem ser verificados na matriz a seguir: método de contenção (reforço de solo - Quadro 1; corte de solo - Quadro 2; ou aterro de solo - Quadro 3); altura limite da contenção, a qual confere se pode ser aplicado abaixo do nível d'água (NA) e se é necessário prever o acesso de maquinário pesado. As vantagens e desvantagens apresentadas também são um compilado do apresentado na literatura, de forma a auxiliar na escolha de uma solução, entre as possíveis, para um mesmo cenário. 


\section{QUADRO 1}

Matriz de tomada de decisão - Reforço de solo.

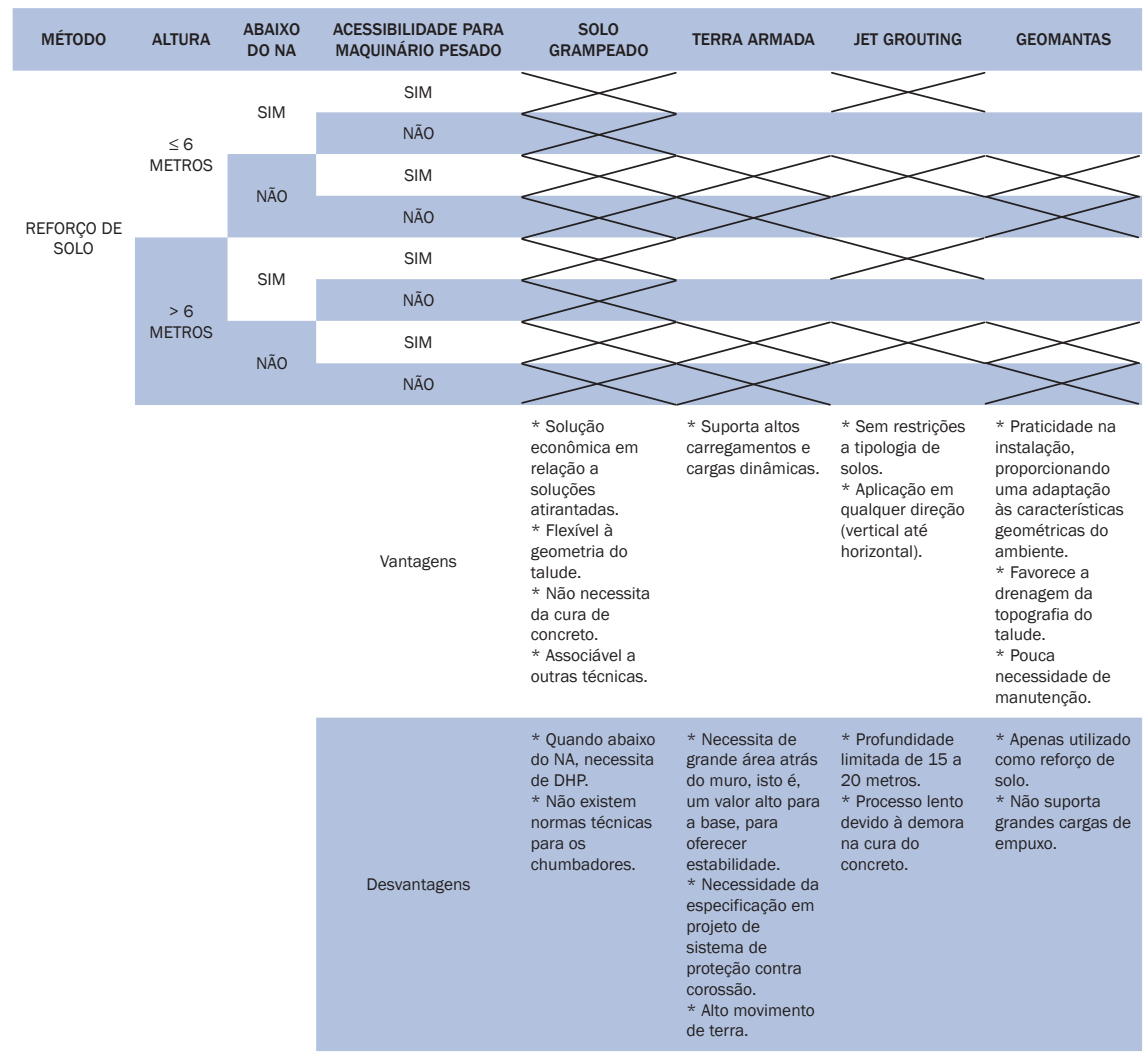

Fonte: Elaborado pelos autores. 
Bianca Fukuhara Yazaki, Gabriel Menegassi Pereira da Silva, Raphael Lacerda Vasconcelos, Victor Shen Tin Hsieh e Kamila Rodrigues Cassares Seko

\section{QUADRO 2}

Matriz de tomada de decisão - Corte.

\begin{tabular}{|c|c|c|c|c|c|c|c|c|c|c|c|c|c|}
\hline MÉTODO & ALTURA & $\begin{array}{l}\text { ABAIXO } \\
\text { DO NA }\end{array}$ & $\begin{array}{l}\text { ACESSIBILI- } \\
\text { DADE PARA } \\
\text { MAQUINRAIO } \\
\text { PESADO }\end{array}$ & $\begin{array}{l}\text { RETALUDA- } \\
\text { MENTO }\end{array}$ & GABIÃO & CRIB-WALL & $\begin{array}{l}\text { MURO EM L-A } \\
\text { FLEXX̃O }\end{array}$ & SOLO PNEU & $\begin{array}{l}\text { SACARIA SOLO } \\
\text { CIMENTO }\end{array}$ & $\begin{array}{c}\text { CORTINA } \\
\text { ATIRANTADA }\end{array}$ & ESTACA RAIZ & MICROESTACA & JET GROUTING \\
\hline \multirow{10}{*}{ CORTE } & \multirow{4}{*}{$\begin{array}{c}\leq 6 \\
\text { METROS }\end{array}$} & \multirow{2}{*}{ SIM } & SIM & & & & & & & $>$ & & & \\
\hline & & & NÃO & & & & & & & 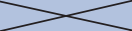 & & & \\
\hline & & \multirow{2}{*}{ NÃ̃ } & SIM & & & & & & & & & & \\
\hline & & & NÃO & & & & & & & $>$ & & & \\
\hline & \multirow{4}{*}{$\begin{array}{c}>6 \\
\text { METROS }\end{array}$} & \multirow{2}{*}{ SIM } & SIM & & & & & & & $\infty$ & & & $\gg$ \\
\hline & & & NÃO & & & & & & & $\rightarrow$ & & & \\
\hline & & \multirow{2}{*}{ NÃO } & SIM & & & & & & & $\infty$ & & & 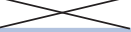 \\
\hline & & & NÃOO & $><$ & & & 3 & & & 3 & & & \\
\hline & & & Vantagens & $\begin{array}{l}\text { * Processo exe- } \\
\text { cutivo simples. } \\
\text { * Pode ser apli- } \\
\text { cado em obras } \\
\text { com altura } \\
\text { superior a } \\
\text { cinco metros } \\
\text { empregando o } \\
\text { métodode esca- } \\
\text { lonamento. }\end{array}$ & $\begin{array}{l}\text { * Baixo impac- } \\
\text { to ambiental. } \\
\text { * Permeável. } \\
\text { * Elemento de } \\
\text { paisagismo. }\end{array}$ & $\begin{array}{l}\text { * Pode ser feito } \\
\text { de pré-molda- } \\
\text { dos. } \\
\text { * Auto drena- } \\
\text { gem que } \\
\text { depende do } \\
\text { agregado uti- } \\
\text { lizado. } \\
\text { * Rápida } \\
\text { execução. }\end{array}$ & $\begin{array}{l}\text { * Muito utiliza- } \\
\text { do e difundido } \\
\text { no mercado. } \\
\text { * Alto custo- } \\
\text { benefício ee } \\
\text { baixas alturas. }\end{array}$ & $\begin{array}{l}\text { * Aproveita- } \\
\text { mento de } \\
\text { pneus descar- } \\
\text { tados. } \\
\text { * Não necessi- } \\
\text { ta de mão de } \\
\text { obra especiali- } \\
\text { zada. }\end{array}$ & $\begin{array}{l}\text { * Controle para } \\
\text { um fluxo de } \\
\text { água que } \\
\text { venha a danifi- } \\
\text { car o solo. } \\
\text { * Não necessi- } \\
\text { ta de mão de } \\
\text { obra especiali- } \\
\text { zada. } \\
\text { *Utilização de } \\
\text { material local. }\end{array}$ & $\begin{array}{l}\text { * Suporta altas } \\
\text { cargas de } \\
\text { empuxo de ter- } \\
\text { ra. } \\
\text { * Pode ser utili- } \\
\text { zada em encos- } \\
\text { tas naturais, } \\
\text { obras nas rodo- } \\
\text { viass ferrovias, } \\
\text { aterros. } \\
\text { * Com as corti- } \\
\text { nas atirantadas } \\
\text { é possível ven- } \\
\text { cer qualquer } \\
\text { altura e situa- } \\
\text { ção. } \\
\text { × Não depen- } \\
\text { dem de } \\
\text { nenhum outro } \\
\text { apoio. }\end{array}$ & $\begin{array}{l}\text { * Qualquer tipo } \\
\text { de solo ou } \\
\text { rocha. } \\
\text { * Suporta altas } \\
\text { cargas de } \\
\text { empuxo de ter- } \\
\text { ra. } \\
\text { * Pode ser utili- } \\
\text { zada em encos- } \\
\text { tas naturais, } \\
\text { obras nas rodo- } \\
\text { viass ferrovias, } \\
\text { aterros. } \\
\text { * Pode ser ins- } \\
\text { talada em } \\
\text { locais de difííil } \\
\text { acesso. }\end{array}$ & $\begin{array}{l}\text { * Empregada } \\
\text { em diferentes } \\
\text { tipos de solo e } \\
\text { rocha. } \\
\text { * Obras com } \\
\text { grande profun- } \\
\text { didade e incli- } \\
\text { nacôes. } \\
\text { * Não precisa } \\
\text { remover todas } \\
\text { as interferên- } \\
\text { cias para a } \\
\text { entrada de } \\
\text { equipamentos. }\end{array}$ & $\begin{array}{l}\text { * Sem restri- } \\
\text { cỗes à tipologia } \\
\text { de solos. } \\
\text { *Aplicacão em } \\
\text { qualaquer dire- } \\
\text { cãao (vertical } \\
\text { até horizontal). }\end{array}$ \\
\hline & & & Desvantagens & $\begin{array}{l}\text { * Alto movimento } \\
\text { de terra. } \\
\text { * Necessita ter } \\
\text { espacoco suficien- } \\
\text { te para alcançar } \\
\text { a declividade } \\
\text { necessária. }\end{array}$ & $\begin{array}{l}\text { * Necessária } \\
\text { grande largura } \\
\text { para a base. }\end{array}$ & $\begin{array}{l}\text { * Pouco difun- } \\
\text { dido no Brasil, } \\
\text { logo pouca } \\
\text { mâo de obra } \\
\text { qualificacada. } \\
\text { * Antieconômi- } \\
\text { co entre } 5 \text { e } 7 \\
\text { metros. } \\
\text { * Risco de tom- } \\
\text { bamento se } \\
\text { mal dimensio- } \\
\text { nado }\end{array}$ & $\begin{array}{l}\text { * Antieconômi- } \\
\text { co entre } 5 \text { e } 7 \\
\text { metros (por } \\
\text { causa da } \\
\text { necessidade de } \\
\text { contraforte). } \\
\text { * Necessario } \\
\text { detalhamento } \\
\text { de drenagem. } \\
\text { * Risco de tom- } \\
\text { bamento se } \\
\text { mal dimensio- } \\
\text { nado. }\end{array}$ & $\begin{array}{l}\text { * Muro pesado, } \\
\text { então possui } \\
\text { limitação de } \\
\text { altura e de } \\
\text { base. }\end{array}$ & $\begin{array}{l}\text { * Processo } \\
\text { demorado. } \\
\text { * Não atinge } \\
\text { grandes } \\
\text { alturas. }\end{array}$ & $\begin{array}{l}\text { * Necessidade } \\
\text { de empresas } \\
\text { especializadas } \\
\text { com equipa- } \\
\text { mentos e mão } \\
\text { de obra ade- } \\
\text { quada. } \\
\text { *Alto custo } \\
\text { para a instala- } \\
\text { cão. } \\
\text { * Longo prazo } \\
\text { para a execu- } \\
\text { cãa desse tipo } \\
\text { de contenção }\end{array}$ & $\begin{array}{l}\text { * Necessidade } \\
\text { de empresas } \\
\text { especializadas } \\
\text { com equipa- } \\
\text { mentos e mão } \\
\text { de obra ade- } \\
\text { quados. } \\
\text { * Por ser uma } \\
\text { fundacão pro- } \\
\text { funda, deve } \\
\text { tomar cuidado } \\
\text { com o recalque } \\
\text { em locais que } \\
\text { ultrapasse o } \\
\text { lencol freático. } \\
\text { *Alto consumo } \\
\text { de cimento e } \\
\text { ferragens. } \\
\text { * Grande } \\
\text { impacto } \\
\text { ambiental. }\end{array}$ & $\begin{array}{l}\text { * Necessidade } \\
\text { de mão deo obra } \\
\text { especializada e } \\
\text { conheneimento } \\
\text { da técnica. } \\
\text { * Pode ser utili- } \\
\text { zado tubo de } \\
\text { PVC rigido no } \\
\text { lugar de tubo } \\
\text { de aço, mas a } \\
\text { armadura é } \\
\text { necessária. }\end{array}$ & $\begin{array}{l}\text { * Profundidade } \\
\text { limitada de } 15 \\
\text { a } 20 \text { metros. } \\
\text { * Processo len- } \\
\text { to devido à } \\
\text { demora na cura } \\
\text { do concreto. }\end{array}$ \\
\hline
\end{tabular}

Fonte: Elaborado pelos autores. 


\section{QUADRO 3}

Matriz de tomada de decisão - Aterro.

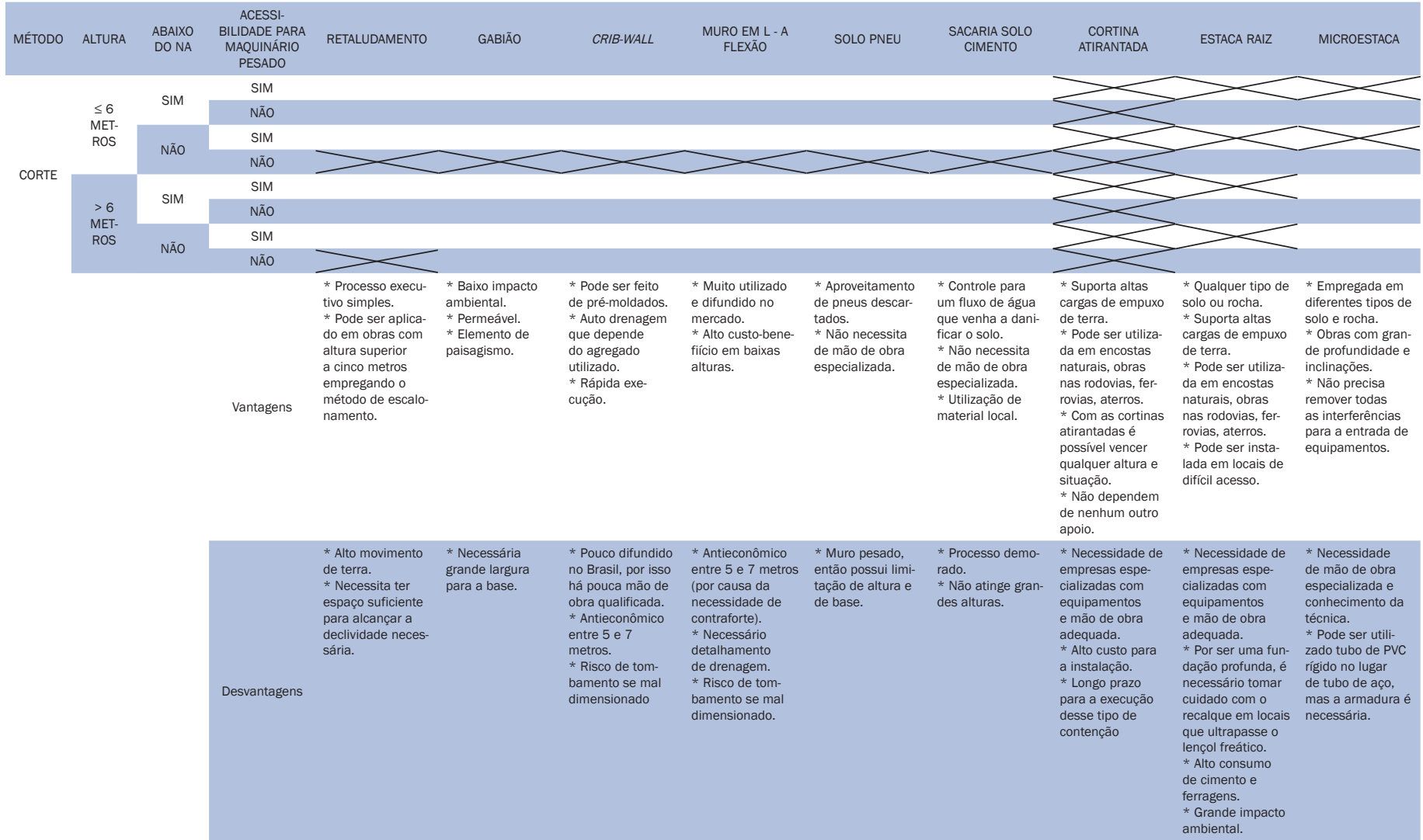

Fonte: Elaborado pelos autores 


\subsection{Estudo de caso}

Foram selecionados quatro locais catalogados pela Defesa Civil do Estado de São Paulo, os três primeiros com obras de contenção já executadas pela Defesa Civil e o último sem uma solução técnica de contenção para a matriz de tomada de decisão a ser aplicada. As áreas selecionadas ficam na subprefeitura de São Mateus (Figura 1) e foram disponibilizadas em Sáo Paulo (2010a) por meio de um relatório técnico $\left(\mathrm{n}^{\circ}\right.$ 117.428-205) desenvolvido pela Prefeitura do Município de Sáo Paulo (PMSP) em parceria com o Instituto de Pesquisas Tecnológicas do Estado de São Paulo (IPT), no ano de 2010.

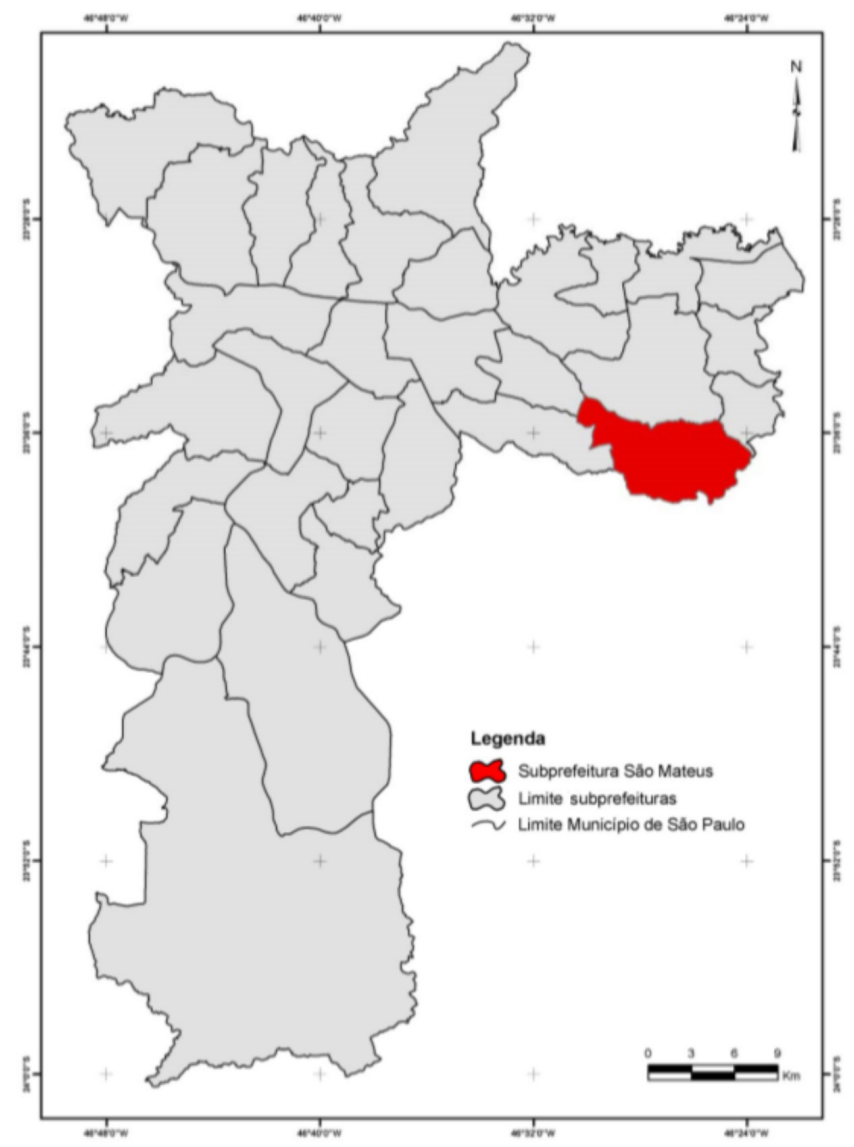

Figura 1 Localização da Subprefeitura de São Mateus.

Fonte: São Paulo (2010a, p. 9). 


\subsubsection{Aplicação da matriz de tomada de decisão em casos reais com soluçóes técnicas propostas}

Com o intuito de estudar o comportamento da matriz de tomada de decisão, construída a partir de sua aplicação, foram selecionadas três áreas localizadas na Subprefeitura de São Mateus com características geológicas e solução de contenção diferentes entre si. Dessa maneira, será possível verificar o comportamento em casos reais a partir de dados reais coletados.

\subsubsection{Jardim Arantes}

A área mapeada está localizada entre as ruas Amoreira Preta e Nogueira de Iguape, no Jardim Arantes, setor SM-19-03, conforme a Figura 2. A região é composta por moradias de alvenaria na base do talude, a taxa de ocupação é parcialmente consolidada, onde a densidade varia de $30 \%$ a $70 \%$ e possui uma infraestrutura básica. Segundo São Paulo (2010b), essa área foi classificada com grau de risco alto (R3), em que a possibilidade de escorregamento é alta no caso nenhuma medida seja adotada durante o período de chuvas intensas no intervalo de um ano.

Alguns dados coletados da ficha de campo do relatório técnico:

1. trata-se de uma encosta;

2. apresenta vias pavimentadas;

3. altura máxima da encosta natural $15 \mathrm{~m}$;

4. altura máxima do talude em corte $4 \mathrm{~m}$;

5. inclinação do talude $70^{\circ}$;

6. área de concentração de água de chuvas na superfície;

7. apresenta vegetação rasteira;

8. não há a presença de nível d'água.

Ao analisar a área com as informaçóes disponibilizadas na ficha de campo de São Paulo (2010b) e aplicando-se a matriz de tomada de decisão, é possível considerar as seguintes soluçôes técnicas: retaludamento; gabião; crib-wall; muro em L; solo pneu; sacaria de solo cimento; cortina atirantada; e microestaca, uma vez que a região é composta por taludes de corte com uma altura máxima de $4 \mathrm{~m}$ e uma inclinação de 90. Encontra-se acima do nível d'água, mas possui uma concentração de água de chuva na superfície; com isso, é necessário prever um sistema de drenagem adequado. A partir das possíveis soluções, apresentamos as vantagens e desvantagens para definir a solução técnica a ser adotada:

1. Retaludamento: apesar de ser um método considerado simples, durante sua execução é necessária uma grande movimentação de solo e uma área em 
planta suficiente para alcançar a declividade do talude que se faz necessária. Com a Figura 2, pode-se observar que essas duas necessidades não serão atendidas no local.

2. Gabiāo: há a necessidade de grande área disponível para alocar a magnitude da largura para a base do muro, já que se trata de um muro de gravidade, e de disponibilidade de material próximo ao local para preenchimento das caixas que o compóem.

3. Crib-wall: apresenta grandes vantagens, porém é pouco difundido no Brasil. Logo, há pouca mão de obra qualificada para a execução de tal método, o que pode gerar maior risco de tombamento, devido a erros de projeto e execuçáo.

4. Muro em L: muito utilizado em obras de contenção e alto custo-benefício, porém é necessário o detalhamento de drenagem e corre o risco de tombamento se mal dimensionado.

5. Solo pneu: apesar do aproveitamento de pneus descartados, o uso desse método de solução não proporciona uma boa estética ao ambiente residencial.

6. Sacaria de solo cimento: apresenta um processo de construção lento, não sendo solução viável para situaçôes emergenciais.

7. Cortina atirantada: apresenta muitas vantagens como listadas no Quadro 2. Entretanto, necessita de empresa especializada para execução, além de apresentar alto custo de instalação e ritmo de construção lento.

8. Microestaca: as manobras necessárias para o equipamento podem dificultar esse método, uma vez que as moradias estão próximas da encosta, como pode ser verificado na Figura 2. 


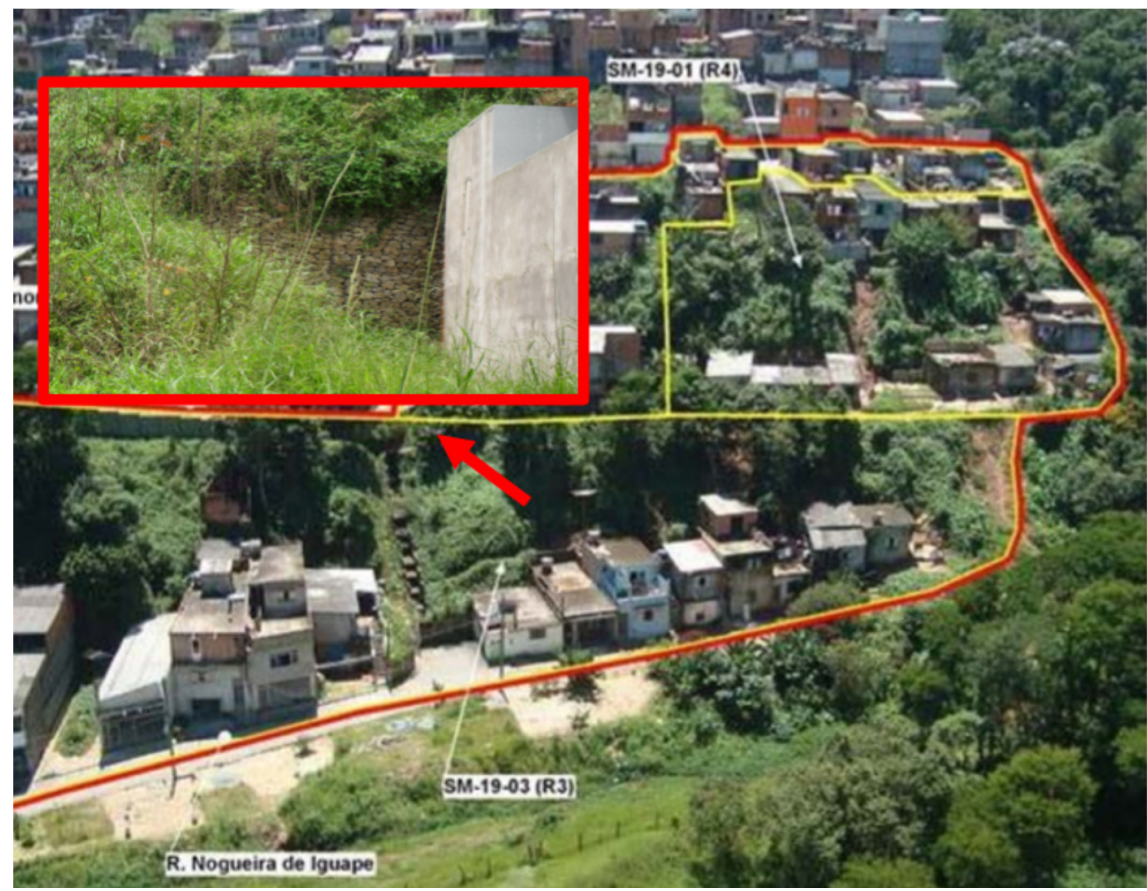

Figura 2 Vista parcial do Jardim Arantes com a aplicação do muro de gabião no setor SM-19-03.

Fonte: Adaptado de São Paulo (2010b, p. 236 e 246).

Ao verificar todas as possibilidades dadas pela matriz e ponderar seus empregos no local descrito, chegou-se à conclusão de que o melhor método a ser empregado seria o gabião. Ressalta-se que se trata do mesmo tipo de obra de contenção utilizada pelo IPT (Figura 2). Como apresentado anteriormente, o muro de gabião possui baixo impacto ambiental e é permeável, funciona como elemento paisagístico e, mesmo tendo moradias com uma distância de cinco metros em relação à sua base, a região possui o espaço necessário para a largura do muro.

\subsubsection{Jardim Recanto Verde II}

O local demarcado fica entre as ruas Recanto do Sol e Independência, no Jardim Recanto Verde II, setor SM-05-05, ilustrado na Figura 3 a seguir. A região já é pavimentada e tem moradias em alvenaria na base e no topo do talude, a taxa de ocupação não é totalmente consolidada - a densidade varia de 30\% a 90\% - e possui uma infraestrutura básica. Segundo Sáo Paulo (2010a), foi classificado com o grau de risco médio (R2), onde existe a baixa possibilidade de escorregamento se nenhuma medida 
for tomada durante o período de chuvas intensas em um ano. Ainda, verificou-se que a distância de moradias do topo e da base está entre $0,0 \mathrm{~m}$ e 1,0 m.

Outros dados coletados da ficha de campo do relatório técnico:

1. trata-se de uma encosta;

2. apresenta vias pavimentadas;

3. altura máxima da encosta natural $50 \mathrm{~m}$;

4. altura máxima do talude em corte $2 \mathrm{~m}$;

5. talude apresenta inclinação de $45^{\circ}$;

6. área de concentração de água de chuvas na superfície;

7. apresenta vegetação rasteira;

8. não há presença de nível d'água.

Com essas informaçóes, pode-se empregar a matriz proposta neste trabalho e levantar as possíveis soluçóes: solo grampeado; terra armada; jet grouting e geomantas. A partir dessas escolhas, é possível analisar as vantagens e desvantagens desses métodos:

1. terra armada: é um método com muitas vantagens; entretanto, para esse caso, torna-se possivelmente inviável devido à movimentação de solo necessária para sua execução. Existem muitas casas próximas ao talude que podem inviabilizar a sua construção;

2. jet grouting: a movimentação do maquinário pode se tornar inviabilizada pela proximidade das casas na região;

3. geomantas: utilizadas como solução única, não deve apresentar capacidade de contribuir para os riscos de deslizamento eminentes da encosta;

4. solo grampeado: devido à adaptabilidade do método em relação à geometria do talude, é a solução mais viável. Não exige remoção dos moradores do entorno e é um processo rápido e econômico. Destaca-se a necessidade de plataformas para trabalho em altura ou alpinismo industrial.

A partir das análises realizadas sobre as soluçóes obtidas com o emprego da matriz, a solução mais viável para esse caso seria a de solo grampeado. Ressalta-se que essa metodologia está de acordo com a solução escolhida pela Defesa Civil de São Paulo, podendo ser visualizada na Figura 3: 


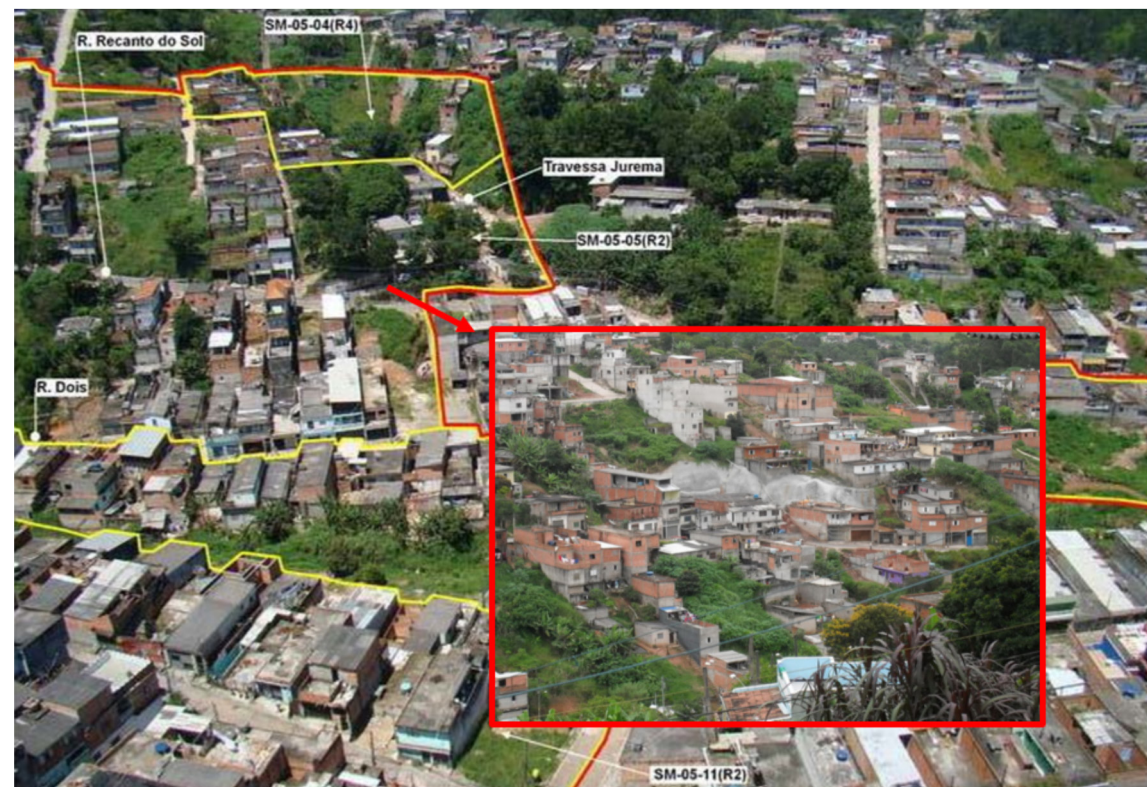

Figura 3 Vista parcial do Jardim Recanto Verde II com a aplicação do solo grampeado no setor SM-05-05.

Fonte: Adaptada de São Paulo (2010a, p. 175 e 200).

\subsubsection{Jardim Recanto Verde I}

O setor SM-01-01 mapeado pelo IPT fica entre as ruas Pedro Ramazzani, Giovanni Mosel e Giácomo Ruffoni, no Jardim Recanto Verde I. A área foi classificada com o grau de risco alto (R3), onde existe alta possibilidade de escorregamento se nenhuma medida for adotada durante o período de chuvas intensas no intervalo de um ano, uma vez que já existem evidências de movimentação, como degraus de abatimento e trincas no terreno. Além disso, foram identificadas moradias com uma distância de 1,5 metros do pé do talude (SÃO PAULO, 2010a).

Dados coletados da ficha de campo do relatório técnico:

1. trata-se de uma encosta;

2. apresenta vias pavimentadas;

3. altura máxima da encosta natural $12 \mathrm{~m}$;

4. altura máxima do talude em corte $2 \mathrm{~m}$;

5. o talude apresenta uma inclinação de $90^{\circ}$;

6. área de concentração de água de chuvas na superfície; 
7. apresenta árvores, vegetação rasteira e área de cultivo de bananeira;

8. não há presença de nível d'água.

A partir dos dados da ficha técnica coletados do relatório técnico e aplicando a matriz de tomada de decisão, têm-se as seguintes possibilidades de contenção: retaludamento; gabiáo; crib-wall; muro em L; solo pneu; sacaria de solo cimento; cortina atirantada; e microestaca. Com esses métodos pré-selecionados, é importante analisar as opçóes de acordo com as vantagens e desvantagens conforme a área mapeada. Como apresentado no Quadro 2, e considerando as características do local de estudo, tem-se:

1. retaludamento: solução inapropriada porque a área em planta é insuficiente para alcançar a declividade do talude almejada, implicando desocupação de moradias próximas;

2. gabiấo: nesse caso, apresentaria grande magnitude para sua base e, por isso, torna-se inaplicável por conta da localização das moradias;

3. crib-wall: não é muito difundida no Brasil e falta mão de obra especializada;

4. muro em L: é uma das soluçôes mais viáveis para esse caso, entretanto, é necessário fazer uma base larga para a contenção das altas cargas das casas acima da encosta;

5. solo pneu: em decorrência do desnível e das cargas oriundas das moradias, esse seria um muro pesado, apresentando limitação de base e altura;

6. sacaria solo cimento: processo de execução é lento;

7. cortina atirantada: é um método bastante utilizado no Brasil, recomendado principalmente em cortes de terrenos que precisam suportar grandes cargas ou em solos que possuem baixa resistência, além de serem usados em relevos bastante acidentados. É uma técnica em que a estabilidade é gerada por tirantes protendidos (ancoragens ativas).

8. microestaca: pode ser utilizado em diferentes tipos de situação, mas é uma técnica que exige mão de obra qualificada e tecnologia.

Após analisar as possibilidades, concluiu-se que, nesse caso, o método mais adequado seria a cortina atirantada, como foi sugerido pela Defesa Civil de Sáo Paulo, conforme ilustrado na Figura 4: 


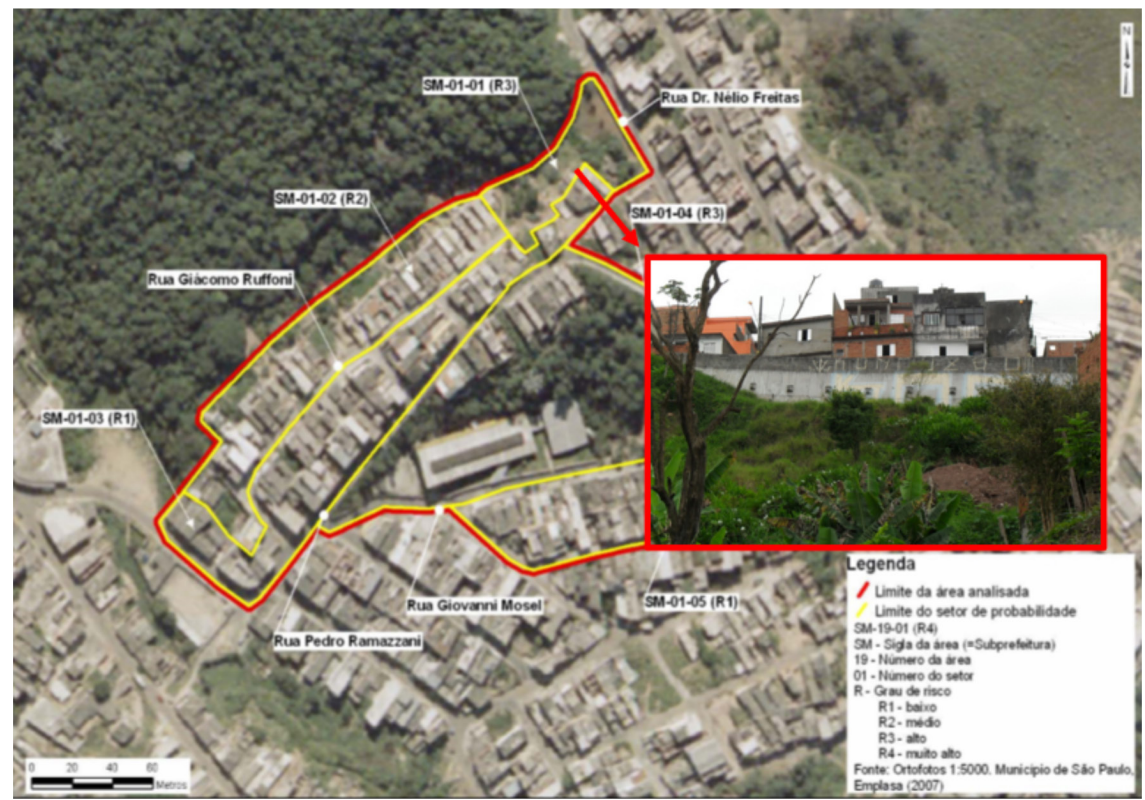

Figura 4 Vista geral do Jardim Recanto Verde I com a aplicação da cortina atirantada no setor SM-01-01.

Fonte: Adaptado de São Paulo (2010a, p. 55 e 61).

\subsubsection{Aplicação da matriz de tomada de decisão em um caso sem solução proposta}

Após a aplicação da matriz nos três casos reais, com soluçóes executadas objetivando estabilizar a encosta, a matriz de tomada de decisão foi empregada em um caso sem uma contenção proposta ou executada, com o intuito de ser utilizada futuramente para facilitar as escolhas de uma forma simples e mais assertiva.

A regiáo escolhida fica localizada no Parque das Flores VI, setor SM-11-01, entre as ruas São José e Gardênia, no Parque das Flores VI, como pode ser visto na Figura 5. O setor mapeado foi classificado com o grau de risco mais elevado (R4) para possíveis escorregamentos. Se, no período de um ano, a precipitação for intensa, é provável que ocorra um evento catastrófico (SÃO PAULO, 2010b). O estudo aponta que na região existe foliação, fator desfavorável à estabilidade do local, e, ainda assim, existem moradias a uma distância de $1 \mathrm{~m}$ do topo e da base do talude. A área está inapropriada para ocupação, uma vez que a região apresenta indícios de movimentação, como trincas nas moradias e cicatrizes de escorregamento (SÃO PAULO, 2010b). 
Alguns dados coletados da ficha de campo do relatório técnico para estudo do caso:

1. trata-se de uma encosta;

2. apresenta vias não pavimentadas;

3. altura máxima da encosta natural $20 \mathrm{~m}$;

4. altura máxima do talude em corte $9 \mathrm{~m}$;

5. o talude apresenta uma inclinaçáo de $90^{\circ}$;

6. área de concentração de água de chuvas na superfície;

7. apresenta árvores, vegetação rasteira e área de cultivo de bananeira;

8. não há presença de nível d'água.

Com as informaçóes coletadas no mapeamento do IPT, é possível aplicar a matriz de tomada de decisão e analisar as possíveis soluçóes para essa área, que tem riscos de um futuro escorregamento. Segundo a matriz, pode-se usar as seguintes soluçóes técnicas: retaludamento; muro em L; cortina atirantada; solo grampeado; terra armada e geomantas.

1. retaludamento: é aconselhável a utilização desse método por ser simples e eficaz, podendo ser utilizado para obras acima de $5 \mathrm{~m}$ de altura, fazendo a utilização, por sua vez, do método de escalonamento, como nessa situação. Por ser uma encosta de altura elevada, necessita ter espaço suficiente para atender uma declividade adequada e evitar novos deslizamentos, e, possivelmente, terá como consequência um alto movimento de terra. As propriedades ao entorno dessa área de risco deverão ser desapropriadas, pois o método necessita de grande extensão para sua execução, conforme enunciado anteriormente;

2. muro em L: é uma solução bastante difundida e utilizada no mercado. Possui um alto custo-benefício em obras em que a altura não é elevada, mas fica antieconômico para obras com alturas acima de $5 \mathrm{~m}$, uma vez que é necessária a construção de contraforte. Além disso, precisa de detalhamento de drenagem; caso seja mal dimensionado, pode ocorrer tombamento;

3. cortina atirantada: esse método é muito utilizado em obras de contenção de encostas em todo o Brasil. É um método muito eficiente, pois suporta elevadas cargas de empuxo de terra, podendo ser utilizado em encostas naturais. Sua estrutura é capaz de vencer grandes alturas sem depender de apoio (como bases largas ou contrafortes), evitando a desapropriação das moradias no entorno. Para a sua execução, é necessário ter prazos mais longos, pois é um processo demorado e necessita de empresas especializadas;

4. solo grampeado: esse método é utilizado para obras de contenção com a funcionalidade de reforço de solo, sendo eficiente e flexível à geometria do 
terreno local. Não é necessária a espera pela cura do concreto, sendo associável a outras técnicas com mais facilidade. Todavia, a falta de normas técnicas para os chumbadores pode se tornar uma desvantagem, pois essas servem para garantir a qualidade da execução da obra;

5. terra armada: suporta altos carregamentos e cargas dinâmicas, além da construção rápida e ter boa aparência, mas, para a sua aplicação, é necessário garantir espaço suficiente com grande largura atrás do muro para evitar desestabilização e, dessa forma, tem-se um alto movimento de terra. Além disso, é necessária a especificação de sistema anticorrosivo em projeto para minimizar a corrosão das barras a longo prazo;

6. geomantas: é um tipo de reforço de solo, esse método destaca-se pela praticidade de execução, de forma a adaptar o material de contenção às geometrias do ambiente, favorecendo a drenagem da topografia local. Mesmo possuindo a vantagem de pouca manutenção, é um método não indicado para locais que estejam submetidos a empuxo de elevada magnitude.

A partir da análise de todas as possibilidades de contenção de encostas que foram obtidas pela aplicação da matriz de tomada de decisão proposta, em conjunto à avaliação das condiçóes do local, como pode ser observado na Figura 5 apresentada a seguir, sugere-se a utilização de solo grampeado ou retaludamento. A segunda opçáo seria inviável, de certa forma, pois, além de causar remoção de famílias, seria necessária uma grande movimentação de terra no local que possibilitasse uma adequação da inclinação de talude e proporcionasse coeficiente de segurança apropriado, segundo a norma técnica vigente. Portanto, sugere-se a utilização do solo grampeado para a estabilização da área afetada, evitando futuros deslizamentos de terra. 


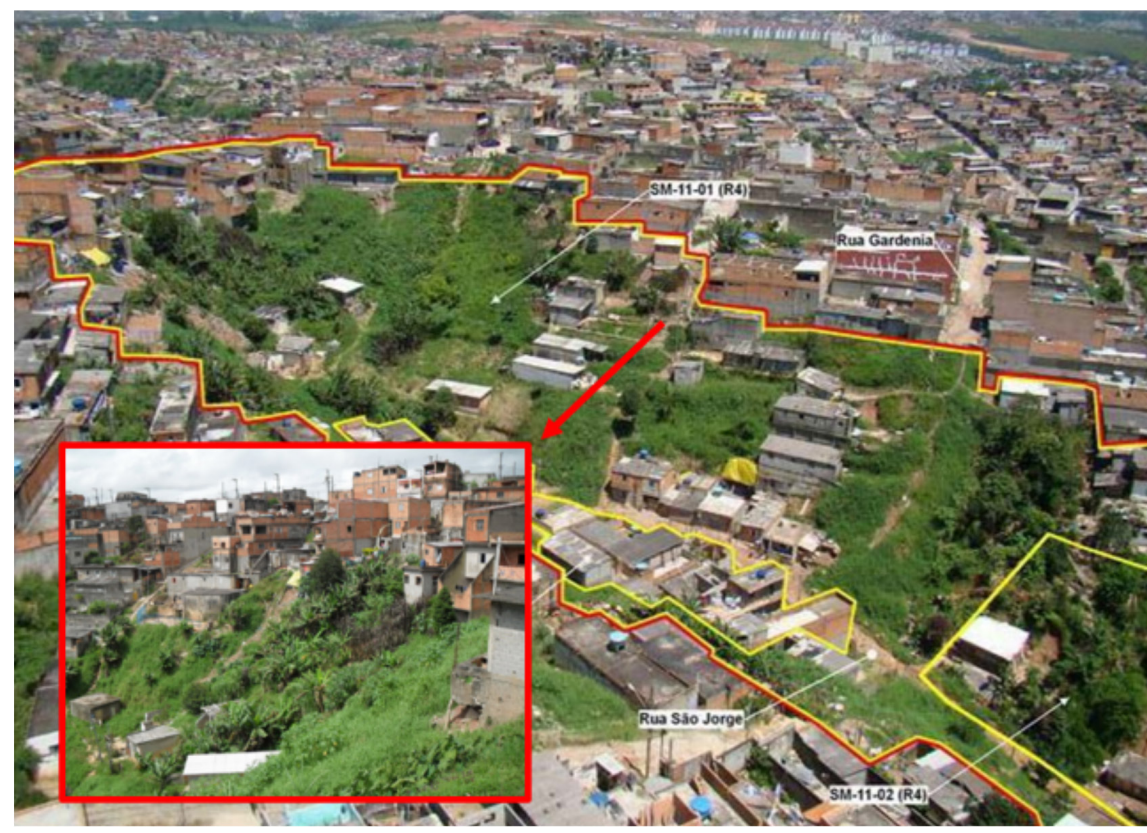

Figura 5 Vista do setor SM-11-01 mapeados com a região que necessita da obra de contenção.

\section{CONSIDERAÇÓES FINAIS}

O problema de escorregamento de terra em regiōes com ocupação antrópica é recorrente, os noticiários relatam, frequentemente, inúmeros desastres que geram grande número de vidas perdidas, principalmente em épocas de chuvas. Com isso, este trabalho teve o objetivo de analisar soluções técnicas para estabilização e contenção de encostas em áreas urbanas com ocupação antrópica. Além disso, foi proposta a criação da matriz de tomada de decisão a partir de seu comportamento, por meio de aplicaçôes práticas da matriz estabelecida em obras já executadas, e o emprego em uma área sem solução técnica. 
Após a análise de três locais situados na Subprefeitura de São Mateus, do Município de São Paulo, pode-se considerar que a matriz de tomada de decisão proposta neste trabalho teve bom desempenho ao ser empregada nos casos selecionados, com soluçôes técnicas executadas.

Com o emprego da matriz de tomada de decisão em um local selecionado a partir dos apresentados por São Paulo (2010b), devido à inexistência de execução de uma contenção, obtiveram-se resultados coerentes. Entretanto, é importante ressaltar que, na construção da matriz, não foi levada em consideração a viabilidade técnico-econômica dos custos humanos, como a remoção e realocação de pessoas. Além disso, ela contempla apenas o cenário em que o subsolo é composto por solo.

Considera-se que os objetivos do trabalho foram atendidos. Também se sugere para futuras pesquisas a validação da matriz de tomada de decisão com uma amostra de dados significativa; a complementaçáo da matriz de tomada de decisão para aplicação em cenários com necessidade de conter ou estabilizar encostas rochosas; a inserção de soluçôes, na matriz de tomada de decisão, não abordadas neste trabalho, como muros de alvenaria de pedra, muro de concreto ciclópico e biocimentaçáo. Além disso, propóe-se acrescentar novos parâmetros para a entrada na matriz, como variação climática, tempo de execução e custo da obra.

\title{
ANALYSIS OF RETAINING WALL AND SOIL REINFORCEMENT TECHNIQUES ON SLOPES WITH ANTHROPIC OCCUPATION
}

\begin{abstract}
This paper presents a study about possible technical solutions applied to provide slope stability in soil failure. It is known that the anthropic and disorderly occupation of hillsides is common in Brazil due to housing shortages. In this way, the stabilization methods were studied to raise their executive limitations and then compose a decision-making matrix. This decision matrix presents as main input these parameters: retaining wall, limit height for retaining wall, whether it can be applied below the water level and whether heavy machinery access is required. As the intention of applying it, three slope stabilization sites were selected. That occurred in the Subprefecture of São Mateus, São Paulo - SP. After a thorough analysis of the possible solutions obtained through the decision matrix, it was verified that a good performance remained when employing the decision-making matrix in a situation of real slope instability.
\end{abstract}

Keywords: Anthropic Occupation. Slope stability. Decision-making matrix. 


\section{REFERÊNCIAS}

CENTRO NACIONAL DE MONITORAMENTO E ALERTA DE DESASTRES NATURAIS - CEMADEN. Movimentos de massa, 2016. Disponível em: https://www.cemaden. gov.br/deslizamentos/. Acesso em: 9 out. 2019.

CORTEZ, B. N. et al. Proposta de Intervenção em Área de Alto Risco em Viçosa - MG Estudo De Caso. In: CONFERÊNCIA BRASILEIRA DE ENCOSTAS (COBRAE), 12., 2017, Florianópolis. Anais [...]. Florianópolis: ABMS, 2017.

ESPÍRITO SANTO. Defesa Civil do Espírito Santo. Coordenadoria Estadual de Proteção e Defesa Civil. Estabilização de Taludes, 2017. Disponível em: https://defesacivil.es.gov.br/Media/defesacivil/Capacitacao/Material\%20Did\%C3\%A1tico/CBPRG\%20-\%202017/ Estabiliza\%C3\%A7\%C3\%A3o_de_Taludes.pdf. Acesso em: 30 nov. 2019.

BRASIL. Departamento Nacional de Infraestrutura de Transporte (DNIT). DNIT 072: tratamento ambiental de áreas de uso de obras e do passivo ambiental de áreas íngremes ou de difícil acesso pelo processo de revegetação herbácea - especificação de serviço. Rio de Janeiro: Ministério dos Transportes, 2006. 23 p. Disponível em: http://ipr.dnit.gov.br/ normas-e-manuais/normas/especificacao-de-servicos-es/dnit072_2006_es.pdf. Acesso em: 9 nov. 2019.

GERSCOVICH, D. Estabilidade de taludes. São Paulo: Oficina de Textos, 2012.

GEOFIX. Estaca Raiz. 2018. Disponível em: http://www.geofix.com.br/servico-estaca-raiz. php\#. Acesso em: 10 out. 2019.

GEORIO. Secretaria Municipal de Obras. Manual técnico de encostas: análise e investigação. 2. ed. Rio de Janeiro: Insitutek Consultores Ltda., 2000a. 1 v.

GEORIO. Secretaria Municipal de Obras. Manual técnico de encostas: drenagem e proteçâo superficial. 2. ed. Rio de Janeiro: Insitutek Consultores Ltda., 2000b. 2 v.

GEORIO. Secretaria Municipal de Obras. Manual técnico de encostas: muros. 2. ed. Rio de Janeiro: Insitutek Consultores Ltda., 2000c. 3 v.

GEORIO. Secretaria Municipal de Obras. Manual técnico de encostas: ancoragens e grampos. 2. ed. Rio de Janeiro: Insitutek Consultores Ltda., 2000d. 4 v.

GIRÃO, O.; CORRÊA, A. C. de B.; GUERRA, A. J. T. Encostas urbanas como unidades de gestão e planejamento, a partir do estudo de áreas a sudoeste da cidade do Recife, Pernambuco. Revista de Geografia, v. 24, n. 3, p. 242-267, 2007.

HACHICH, W. et al. Fundaçôes: teoria e prática. 2. ed. São Paulo: Pini, 1998.

INSTITUTO BRASILEIRO DE GEOGRAFIA E ESTATÍSTICA - IBGE. População em áreas de risco no Brasil. Brasília: IBGE, 2018. Disponível em: https:/www.ibge.gov.br/apps/ populacaoareasderisco/. Acesso em: 29 abr. 2021. 
LEITE, G. T. D.; PINHEIRO, R. Z. G.; PAMBOUKIAN, S. V. D. Monitoramento de áreas de risco com a utilização de técnicas de geoprocessamento. Revista Mackenzie de Engenharia e Computação, São Paulo, v. 19, n. 1, p. 28-47, 2019.

LUZ, P. A. et al. Ocupação antrópica de encostas e sua estabilização. In: TULLIO, F. B. M. Enfoques e possibilidades para a engenharia geotécnica. Ponta Grossa: Atena Editora, 2019. p. 78-90.

MASSAD, F. Obras de Terra: curso básico de geotecnia. 2. ed. São Paulo: Oficina de Textos, 2010.

MESAVILLA, D. T. Sabes qual a importância de um Estudo Estabilidade de Talude? M3 Geologia e Meio Ambiente, 2019. Disponível em: https://www.mbgeologia.com.br/novidades/ detalhe/26/sabes-qual-a-import-ncia-de-um-estudo-estabilidade-de-talude. Acesso em: 22 set. 2019.

MINISTÉRIO DAS CIDADES; INSTITUTO DE PESQUISAS TECNOLÓGICAS - IPT. Mapeamento de riscos em encostas e margem de rios. Brasília, DF: IPT, 2007.

PESSÔA NETO, D. P. Tipos de escorregamentos e importância de estudos geotécnicos. São Paulo: Instituto Brasileiro do Desenvolvimento da Arquitetura, 2013. Disponível em: http://www.forumdaconstrucao.com.br/conteudo.php?a=9\&Cod=888. Acesso em: 25 nov. 2019.

RIOS FILHO, M. G. et al. Projetos de contenção dos taludes a montante da praça Suspiro em Nova Friburgo - RJ. In: CONFERÊNCIA BRASILEIRA DE ENCOSTAS (COBRAE), 6. 2013, Angra dos Reis. Anais [...]. Angra dos Reis: ABMS, 2013. p. 145-150.

SÃO PAUlO (Município). Centro de Tecnologias Ambientais e Energéticas (CETAE). Prefeitura Municipal de São Paulo (PMSP). Relatório técnico $n^{\circ}$ 117.428-205: análise e mapeamento de riscos associados a escorregamentos em áreas de encostas e a solapamentos de margens de córregos em favelas do município de São Paulo - Subprefeitura de São Mateus. São Paulo: PMSP, 2010a. v. 1. Disponível em: http://www.sidec.sp.gov.br/map_risco/uploads/ doc1475590552.pdf. Acesso em: 18 mar. 2020.

SÃO PAULO (Município). Centro de Tecnologias Ambientais e Energéticas (CETAE); Prefeitura Municipal de São Paulo (PMSP). Relatório técnico $n^{\circ} 117.428-205$ : análise e mapeamento de riscos associados a escorregamentos em áreas de encostas e a solapamentos de margens de córregos em favelas do município de São Paulo - Subprefeitura de São Mateus. São Paulo: PMSP, 2010b. v. II. Disponível em: http://www.sidec.sp.gov.br/ map_risco/uploads/doc1475590651.pdf. Acesso em: 18 mar. 2020.

SOlOTRAT ENGENHARIA GEOTÉCNICA EIRELI. Manual de Serviços Geotécnicos. São Paulo: Solotrat, 2018. 6 v.

SOARES, F. L.; PEREIRA, N. N. T. Proposta de metodologia para mapeamento de risco geológico-geotécnico de escorregamentos em João Pessoa - PB. In: CONFERÊNCIA BRASILEIRA DE ENCOSTAS (COBRAE), 7., 2017, Florianópolis. Anais [...]. Florianópolis: ABMS, 2017. 
SOUZA, L. do V. et al. Método para avaliaçáo de suscetibilidade a movimentos de massa na bacia hidrográfica do córrego Marilândia. In: CONFERÊNCIA BRASILEIRA DE ENCOSTAS (COBRAE), 7., 2017, Florianópolis. Anais [...]. Florianópolis: ABMS, 2017.

\section{Contato}

Kamila Rodrigues Cassares Seko

kamila.seko@mackenzie.br

\section{Tramitação}

Recebido em outubro de 2020.

Aprovado em junho de 2021. 